\title{
Co-reductive fabrication of carbon nanodots with high quantum yield for bioimaging of bacteria
}

\author{
Jiajun Wang ${ }^{1}$, Xia Liu1, Gesmi Milcovich², Tzu-Yu Chen ${ }^{3}$, Edel Durack $^{2}$, Sarah Mallen², \\ Yongming Ruan ${ }^{1}$, Xuexiang Weng ${ }^{* 1}$ and Sarah P. Hudson ${ }^{* 2}$
}

\section{Full Research Paper}

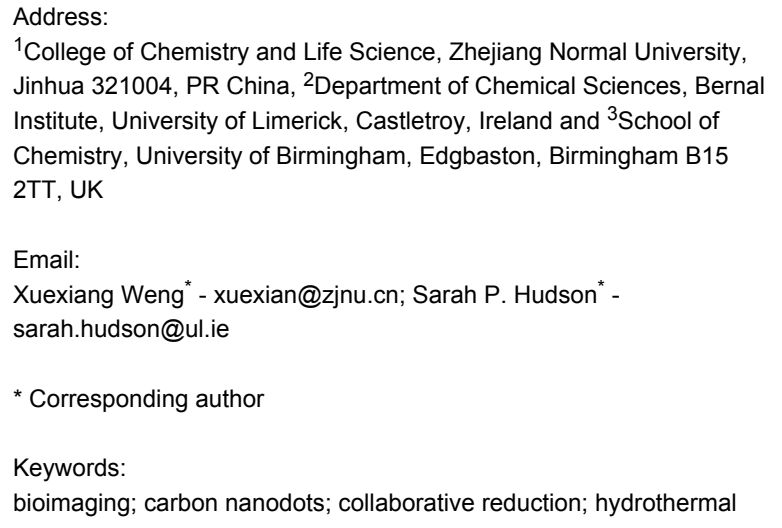

${ }^{1}$ College of Chemistry and Life Science, Zhejiang Normal University, Jinhua 321004, PR China, ${ }^{2}$ Department of Chemical Sciences, Bernal Institute, University of Limerick, Castletroy, Ireland and ${ }^{3}$ School of Chemistry, University of Birmingham, Edgbaston, Birmingham B15 2TT, UK

Beilstein J. Nanotechnol. 2018, 9, 137-145. doi:10.3762/bjnano.9.16

Received: 09 June 2017

Accepted: 19 December 2017

Published: 12 January 2018

Associate Editor: S. A. Claridge

(C) 2018 Wang et al.; licensee Beilstein-Institut. License and terms: see end of document.

\begin{abstract}
A simple and straightforward synthetic approach for carbon nanodots (C-dots) is proposed. The strategy is based on a one-step hydrothermal chemical reduction with thiourea and urea, leading to high quantum yield C-dots. The obtained C-dots are welldispersed with a uniform size and a graphite-like structure. A synergistic reduction mechanism was investigated using Fourier transform infrared spectroscopy and X-ray photoelectron spectroscopy. The findings show that using both thiourea and urea during the one-pot synthesis enhances the luminescence of the generated C-dots. Moreover, the prepared C-dots have a high distribution of functional groups on their surface. In this work, C-dots proved to be a suitable nanomaterial for imaging of bacteria and exhibit potential for application in bioimaging thanks to their low cytotoxicity.
\end{abstract}

\section{Introduction}

Over recent years, carbon nanomaterials have remarkably influenced the growth of a wide range of fields, including electronics, photonics, energy, catalysis and medicine. Within this class of materials, carbon nanodots (C-dots) are deemed a major breakthrough for the development of fluorescent nanomaterials. They are a promising alternative to fluorescent inorganic semiconductor nanocrystals and organic dyes due to their chemical stability, good dispersibility in water, low photobleaching and low cytotoxicity. They show great potential for bioimaging, photocatalysis, energy conversion, fluorescent ink and sensing applications [1-3]. In a bioimaging application perspective, the detection of bacteria by microscopic visualization is an essential benchmark. Currently, visual detection approaches are based on indirect methods related to bacterially secreted metabolites or imaging of bacterial colonies [4]. Furthermore, the staining techniques use either commercially available fluorescent dyes or semiconductor quantum dots [5]. Fluorescent dyes are expensive, instable and easily susceptible to photo- 
bleaching, while the semiconductor quantum dots are toxic and difficult to dissolve in water. Therefore, simple and inexpensive methods to visualize the morphological details of bacterial cells are highly needed.

C-dots can thus be proposed as an innovative platform for bioimaging purposes thanks to their fluorescent features. In this context, the quantum yield (QY) is one of the most important features for C-dot performance. Although, at present, the actual mechanism of the photoluminescence of C-dots is still an open debate among researchers [6-8], significant progress in increasing the QY has been achieved. Most of the mentioned methods refer to surface passivation [9-11] and doping [12,13]. Recently, chemical reduction was also reported as an effective method to enhance the QY of C-dots [14]. Zheng et al. found an increase in QY for C-dots from $2 \%$ to $24 \%$ following reduction with sodium borohydride $\left(\mathrm{NaBH}_{4}\right)$. The same results were confirmed by Shen and Tian's group $[15,16]$. It was also reported that the fluorescence intensity of graphene quantum dots reduced by hydrazine hydrate $\left(\mathrm{N}_{2} \mathrm{H}_{4}\right)$ can be enhanced to more than two times that of the pristine graphene quantum dots [17]. However, this reduction pathway is based on a two-step procedure: firstly, a synthesis and collection of bare C-dots, then a reduction of $\mathrm{C}$-dots to enhance their QY. The above procedure is often time consuming, poses difficulty in achieving a final pure sample, and introduces secondary pollution products. Therefore, in order to promote and extend their range of applications, new methods to obtain C-dots with high QY are required.

Citric acid, citrate, urea or thiourea have been used in the past to obtain high-QY C-dots with different growth mechanisms proposed [18-20]. Qu et al. obtained graphene quantum dots with a quantum yield of $78 \%$ and $71 \%$ using citric acid and urea or citric acid and thiourea as the precursors, respectively. They demonstrated that $\mathrm{N}$ or N/S doping led to the high QY of the C-dots. Zeng et al. prepared C-dots with a relatively high QY value (45\%) using citric acid and urea as precursors via a facile hydrothermal method. They evidenced that surface passivation by urea resulted in the high QY of the C-dots. Herein we report a C-dot synthetic procedure with remarkable QY (37\%) by a one-step hydrothermal chemical reduction method, where sodium citrate is the carbon source and urea and thiourea are the co-reducers. Specifically, the amount of citrate was kept constant and the molar ratio of urea and thiourea were varied to demonstrate the effects of thiourea and urea on the different QYs. The results showed C-dots prepared with both urea and thiourea present more reduced carbon and exhibit a higher QY under the synergistic reduction way. Compared with a conventional two-step chemical reduction pathway, the one-step method is efficient and eco-friendly. Moreover, the obtained $\mathrm{C}$-dots with abundant functional groups on the C-dot surface and high QY exhibit excellent potential for use as bacteria (Xanthomonas axonopodis pv. glycins, Xag) imaging agents.

\section{Results and Discussion Synthesis of carbon nanodots}

As shown in Table 1, the C-dots with different QYs were obtained as the amount of sodium citrate was kept constant and the molar ratio of urea and thiourea was varied. Remarkably, $\mathrm{C}$-dots from sodium citrate, urea and thiourea resulted in a higher QY than those of citrate and urea or citrate and thiourea. To explain the differences in QY for these samples, we propose that sodium citrate serves as a self-assembly trigger for a carbon-based structure due to the intermolecular H-bonding. Subsequently, a condensation process takes place, forming $\mathrm{C}$-dots. Meanwhile, the gradual, homogenous release of $\mathrm{OH}^{-}$ and $\mathrm{NH}_{3}$ from urea hydrolysis [21] and $\mathrm{H}_{2} \mathrm{~S}$ from thiourea led to the formation of $\mathrm{C}$-dots under alkaline, reducing and hydrothermal conditions [22-25]. Therefore, C-dots prepared with both urea and thiourea present a higher amount of reduced carbon and exhibit a higher QY under the co-reduction pathway. It was also found that increasing the thiourea concentration above $0.014 \mathrm{M}$ during the synthesis process resulted in a gradual decrease in QY. The results indicated that it acquired a highest reduced atmosphere when the molar ratio of urea to thiourea is about 3 .

\begin{tabular}{|c|c|c|c|c|}
\hline $\begin{array}{l}\text { Sample } \\
\text { labela }^{a}\end{array}$ & $\begin{array}{l}\text { Sodium citrate } \\
(\mathrm{mmol})\end{array}$ & $\begin{array}{l}\text { Urea } \\
\text { (mmol) }\end{array}$ & $\begin{array}{l}\text { Thiourea } \\
\text { (mmol) }\end{array}$ & QY (\%) \\
\hline $\mathrm{S}_{\mathrm{a}}$ & 0.28 & 1.68 & 0 & 8 \\
\hline$S_{b}$ & 0.28 & 1.26 & 0.42 & 37 \\
\hline $\mathrm{S}_{\mathrm{C}}$ & 0.28 & 0.84 & 0.84 & 20 \\
\hline$S_{d}$ & 0.28 & 0.42 & 1.26 & 14 \\
\hline$S_{e}$ & 0.28 & 0 & 1.68 & 2 \\
\hline
\end{tabular}

aAll the samples were dissolved in $30 \mathrm{~mL}$ of water.

To demonstrate the rationale of co-reduced C-dot production method, glucose and xylose were used as the model carbon source references. Glucose and xylose were selected due to their broad range of use for C-dot fabrication [26,27] and the obtained QYs are shown in Supporting Information File 1, Table $\mathrm{S} 1$. The results further prove that mixed reducing conditions can enhance the QY, irrespective of the carbon source used.

Due to the wide range of C-dot applications, their quantitative yield for mass production must be improved. As shown in Supporting Information File 1,Table S2, 4.0 to $5.0 \mathrm{~g}$ of C-dots were prepared by increasing the concentration of the reagents, while still keeping the molar ratios constant during the synthesis. It 
was found that the QY of the C-dots with co-reduction using urea and thiourea is much higher than when urea or thiourea are used individually during reduction. Moreover, during the scaleup synthesis, it was determined that the C-dots tend to aggregate due to their larger magnitude in mass, leading to an increase in the size of the synthesized C-dots (Figure S1, Supporting Information File 1) and a decrease in the QY.

\section{Characterization of the carbon nanodots}

The morphology of the products was characterized by transmission electron microscopy (TEM) and high-resolution transmission electron microscopy (HRTEM). Figure $1 \mathrm{~A}-\mathrm{C}$ shows the TEM images of the $\mathrm{S}_{\mathrm{a}}, \mathrm{S}_{\mathrm{b}}$ and $\mathrm{S}_{\mathrm{e}}$ samples. As it can be observed, all the C-dots are consistently dispersed and separated from each other. The three samples show lattice fringes with distances of 0.258 (inset in Figure 1A), 0.246 (inset in Figure 1B) and $0.303 \mathrm{~nm}$ (inset in Figure 1C), respectively. These are consistent with the (102), (100) and (002) diffraction planes, respectively, of $\mathrm{sp}^{2}$ graphitic carbon [28,29]. The corresponding particle size distribution histograms (Figure 1D-F) show the average diameter of the $\mathrm{S}_{\mathrm{a}}, \mathrm{S}_{\mathrm{b}}$ and $\mathrm{S}_{\mathrm{e}}$ materials is $4.7 \pm 1.0 \mathrm{~nm}, 2.2 \pm 0.5 \mathrm{~nm}$ and $7.8 \pm 1.8 \mathrm{~nm}$, respectively.

X-ray diffraction (XRD) was used to investigate the crystallinity of $S_{a}, S_{b}$ and $S_{e}$. As shown in Figure $S 2$ in Supporting Information File 1, sample $S_{a}$ and $S_{e}$ display a broad diffraction peak centered at around $22.7^{\circ}$, which is similar to the (002) lattice spacing for graphitic $\left(\mathrm{sp}^{2}\right)$ carbon [30-33]. However, for the pattern of $\mathrm{S}_{\mathrm{b}}$, the peak at $22.7^{\circ}$ is much stronger and an extra peak centered at $15.9^{\circ}$ appears, which refers to the (103) planes of hexagonal carbon [9]. It can be noticed that the crystallite size from the diffraction peaks does not perfectly match with the lattice spacing observed in TEM. This could be ascribed to the fact that the average polycrystalline signal is collected in XRD, while in TEM, only the single crystallite is investigated.

The mean crystallite size of the C-dots was estimated by using Scherrer's equation, $D=k \lambda / \beta \cos \theta$, where $D$ is the average crystallite size, $k$ is a geometrical factor (0.89), $\lambda$ is the wavelength of the monochromatic X-rays ( $\mathrm{Cu} \mathrm{K} \alpha$ radiation, $\lambda=1.5404 \AA$ ), $\theta$ is the Bragg angle and $\beta$ is the full-width at half-maximum intensity of the diffraction peak (in radians) at $2 \theta$ [34]. The average crystallite size of $\mathrm{S}_{\mathrm{a}}, \mathrm{S}_{\mathrm{b}}$ and $\mathrm{S}_{\mathrm{e}}$ calculated from the XRD patterns is $3.3,2.85$ and $3.9 \mathrm{~nm}$, respectively, which is consistent with the size distribution ranges observed in TEM.

In order to further confirm the intrinsic carbogenic structure, the Raman spectra $\left(\lambda_{\mathrm{ex}}=633 \mathrm{~nm}\right)$ of $\mathrm{S}_{\mathrm{a}}, \mathrm{S}_{\mathrm{b}}$ and $\mathrm{S}_{\mathrm{e}}$ are shown in Figure S3, Supporting Information File 1. Two typical peaks for carbon can be clearly detected for $\mathrm{S}_{\mathrm{a}}, \mathrm{S}_{\mathrm{b}}$ and $\mathrm{S}_{\mathrm{e}}$. The D-band, located at $1387 \mathrm{~cm}^{-1}$, correlates to the disorder or defects in the graphitized structure ( $\mathrm{sp}^{3}$-hybridized carbon), while the G-band $\left(1540 \mathrm{~cm}^{-1}\right)$ is assigned to the $\mathrm{E}_{2 \mathrm{~g}}$ mode of graphite and corresponds to the vibration of $\mathrm{sp}^{2}$-bonded carbon atoms in a twodimensional hexagonal [35]. The intensity ratio of the $\mathrm{D}$ - to G-band $\left(I_{\mathrm{D}} / I_{\mathrm{G}}\right)$ is a measure of the extent of disorder, and the ratio of $\mathrm{sp}^{3} / \mathrm{sp}^{2}$ carbon. $\mathrm{S}_{\mathrm{a}}$ has an $I_{\mathrm{D}} / I_{\mathrm{G}}$ ratio of 0.86 , and a ratio of 1 in both $\mathrm{S}_{\mathrm{b}}$ and $\mathrm{S}_{\mathrm{e}}$ was found. The lower $I_{\mathrm{D}} / I_{\mathrm{G}}$ value of $\mathrm{S}_{\mathrm{b}}$ suggests that $\mathrm{S}_{\mathrm{b}}$ is composed of more $\mathrm{sp}^{2}$-bonded carbon atoms
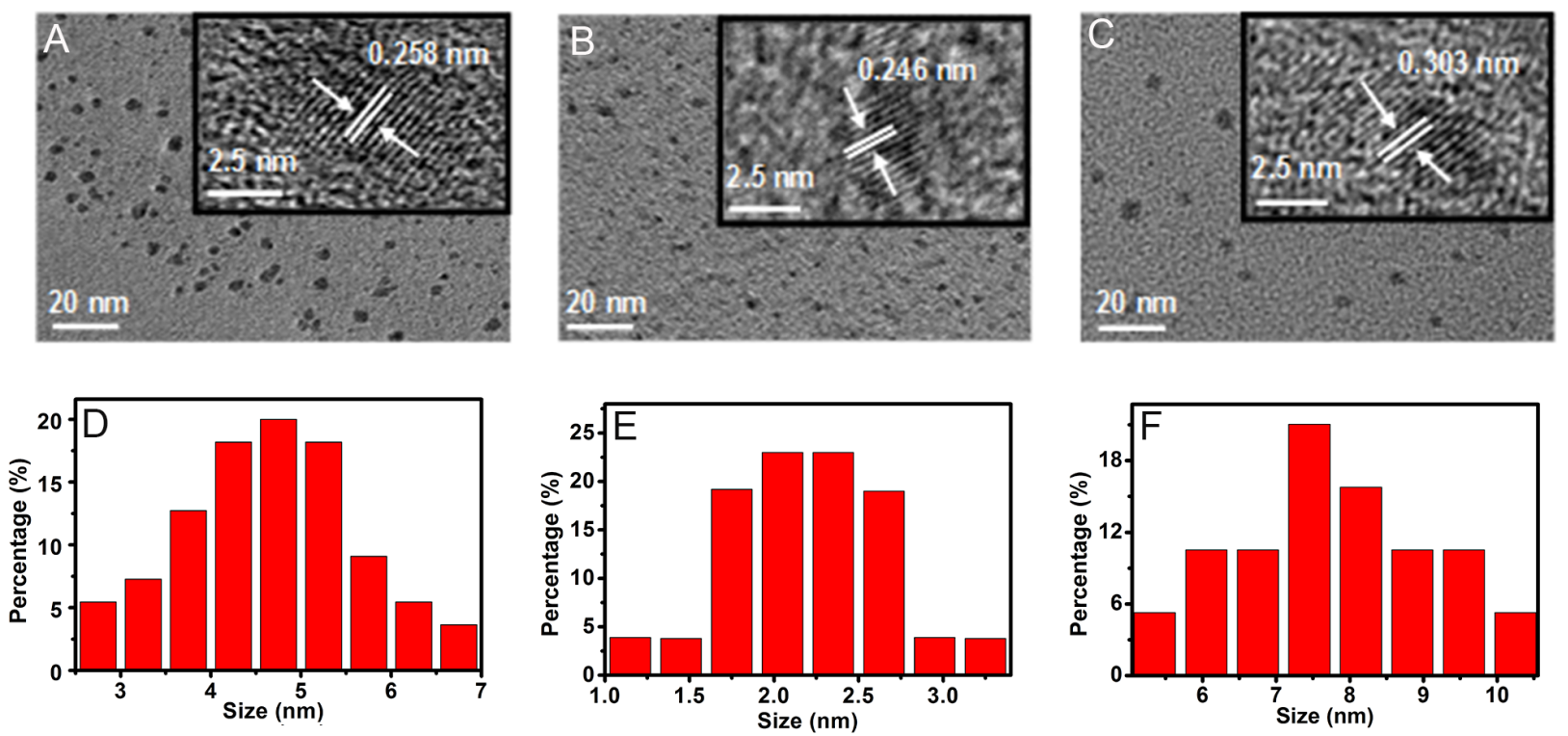

Figure 1: TEM and HRTEM (inset) images of $(A) S_{a},(B) S_{b},(C) S_{e}$ samples, and corresponding size (diameter) distribution ranges for (D) $S_{a}$, (E) $S_{b}$, and $(F) S_{e}$ 
[36], which agrees well with the proposed co-reduction pathway to effectively produce more reduced carbon with a higher C-dot QY.

UV-vis absorption and fluorescence properties were studied at room temperature to explore the optical properties of the three optimized C-dots. As shown in Figure 2A-C, UV-vis spectra of $\mathrm{S}_{\mathrm{a}}, \mathrm{S}_{\mathrm{b}}$ and $\mathrm{S}_{\mathrm{e}}$ all show typical $\mathrm{n} \rightarrow \pi^{*}$ transition absorption peaks at $336 \mathrm{~nm}, 332 \mathrm{~nm}$ and $330 \mathrm{~nm}$, respectively. $\mathrm{S}_{\mathrm{a}}, \mathrm{S}_{\mathrm{b}}$ and $\mathrm{S}_{\mathrm{e}}$ display their highest emission intensity at $430 \mathrm{~nm}, 420 \mathrm{~nm}$ and $430 \mathrm{~nm}$, corresponding to $320 \mathrm{~nm}, 310 \mathrm{~nm}$ and $320 \mathrm{~nm}$ excitation, respectively. The emission wavelengths of $\mathrm{S}_{\mathrm{a}}, \mathrm{S}_{\mathrm{b}}$ and $\mathrm{S}_{\mathrm{e}}$ are dependent on the excitation wavelengths in the range of $300-380 \mathrm{~nm}$, red-shifting with the gradual increase of the excitation wavelength (Figure 2D-F). Furthermore, the fluorescent decay dynamics for $\mathrm{S}_{\mathrm{a}}, \mathrm{S}_{\mathrm{b}}$ and $\mathrm{S}_{\mathrm{e}}$ were also investigated (Figure $2 \mathrm{G}-\mathrm{I}$ ). The time-resolved decay curves of $\mathrm{S}_{\mathrm{a}}$ and $\mathrm{S}_{\mathrm{b}}$ are well fitted with a tri-exponential function, while that of $S_{e}$ is fitted with a bi-exponential function. The fluorescence characteristic parameters, including the excitation $\left(\lambda_{\mathrm{ex}}\right)$ and emission $\left(\lambda_{\text {em }}\right)$ wavelengths, quantum yield $(\Phi)$, lifetime components $\left(\tau_{1}\right.$, $\left.\tau_{2}, \tau_{3}\right)$ and fluorescence lifetime $\left(\tau_{\mathrm{ave}}\right)$ for $\mathrm{S}_{\mathrm{a}}, \mathrm{S}_{\mathrm{b}}$ and $\mathrm{S}_{\mathrm{e}}$ are listed in Table 2 .

Table 2: The excitation $\left(\lambda_{\mathrm{ex}}\right)$ and emission $\left(\lambda_{\mathrm{em}}\right)$ wavelengths, quantum yield $(\Phi)$, lifetime components $\left(\mathrm{T}_{1}, \mathrm{~T}_{2}, \mathrm{~T}_{3}\right)$ and fluorescence lifetime ( $T_{a v e}$ ) for $\mathrm{S}_{\mathrm{a}}, \mathrm{S}_{\mathrm{b}}$ and $\mathrm{S}_{\mathrm{e}}$.

\begin{tabular}{llllllll}
$\begin{array}{l}\lambda_{\mathrm{ex}} \\
(\mathrm{nm})\end{array}$ & $\begin{array}{l}\lambda_{\mathrm{em}} \\
(\mathrm{nm})\end{array}$ & $\Phi$ & $\mathrm{T}_{1}(\mathrm{~ns})$ & $\mathrm{T}_{2}(\mathrm{~ns})$ & $\mathrm{T}_{3}(\mathrm{~ns})$ & $\begin{array}{l}\mathrm{T}_{\text {ave }} \\
(\mathrm{ns})\end{array}$ \\
\hline $\mathrm{S}_{\mathrm{a}} 320$ & 430 & 8 & $\begin{array}{l}0.08 \\
(1.0 \%)\end{array}$ & $\begin{array}{l}3.98 \\
(19.4 \%)\end{array}$ & $\begin{array}{l}7.61 \\
(79.25 \%)\end{array}$ & 6.17 \\
$\mathrm{~S}_{\mathrm{b}}$ & 310 & 420 & 37 & $\begin{array}{l}1.06 \\
(2.82 \%)\end{array}$ & $\begin{array}{l}6.19 \\
(73.68)\end{array}$ & $\begin{array}{l}10.76 \\
(23.5 \%)\end{array}$ & 7.12 \\
$\mathrm{~S}_{\mathrm{e}} 320$ & 430 & 2 & $\begin{array}{l}1.46 \\
(29.3 \%)\end{array}$ & $\begin{array}{l}7.86 \\
(70.7 \%)\end{array}$ & - & 5.98 \\
& & & & & &
\end{tabular}

The FT-IR spectra show the functional groups present in the $\mathrm{C}$-dots (Figure 3). All the samples were found to contain oxygen-based functional groups $(\mathrm{O}-\mathrm{H}, \mathrm{C}-\mathrm{O}, \mathrm{C}=\mathrm{O})$, as well as $\mathrm{N}-\mathrm{H}, \mathrm{C}=\mathrm{C}$, and $\mathrm{C}-\mathrm{N}$ groups. For $\mathrm{S}_{\mathrm{b}}$ and $\mathrm{S}_{\mathrm{e}}$, they have addition-
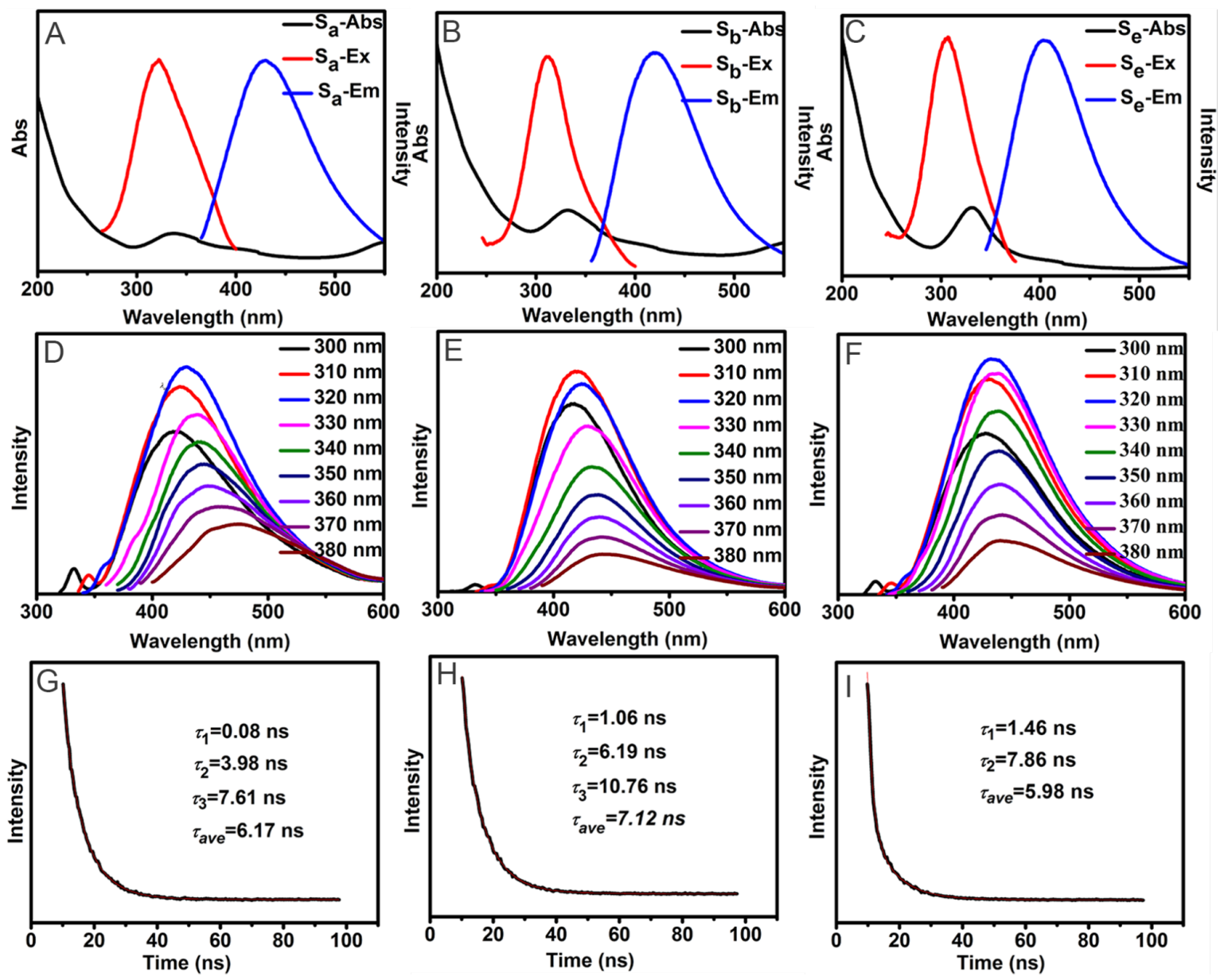

Figure 2: (A-C) UV-vis absorption, excitation and emission spectra, (D-F) fluorescence emission spectra recorded at different excitation wavelengths and $(G-I)$ fluorescence intensity decay curves of $S_{a}, S_{b}$ and $S_{e}$, respectively. 


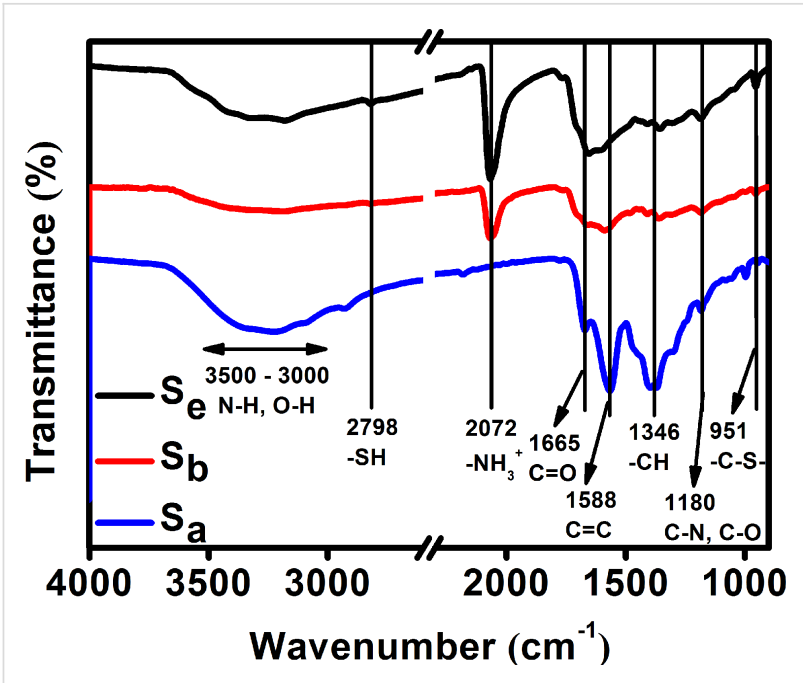

Figure 3: Fourier transform infrared spectra of $\mathrm{S}_{\mathrm{a}}, \mathrm{S}_{\mathrm{b}}$, and $\mathrm{S}_{\mathrm{e}}$.

al $-\mathrm{NH}_{3}{ }^{+}$and sulphur-containing groups, such as $\mathrm{S}-\mathrm{H}$ and $\mathrm{C}-\mathrm{S}$. The weak peak at $1665 \mathrm{~cm}^{-1}$ of $\mathrm{S}_{\mathrm{b}}$ indicates an effective reduction of $\mathrm{C}=\mathrm{O}$ groups.

The chemical composition of the C-dots was further characterized by X-ray photoelectron spectroscopy (XPS) (Figure 4). The $\mathrm{C} 1 \mathrm{~s}$ spectra can be fitted by three Gaussian peaks (Figure 4B), which correspond to the $\mathrm{sp}^{2}$-hybridized olefinic carbons $(\mathrm{C}=\mathrm{C})$, the $\mathrm{sp}^{3}$-hybridized carbons $(\mathrm{C}-\mathrm{O}, \mathrm{C}-\mathrm{S}$, and $\mathrm{C}-\mathrm{N}$ ), and the oxidized carbon in the carboxyl group. For the $\mathrm{S}_{\mathrm{b}}$ sample, the intensity of carboxyl group decreases, whereas the $\mathrm{sp}^{2} \mathrm{C}=\mathrm{C}$ peak increases. Moreover, a higher binding energy of the graphitic carbon in $\mathrm{S}_{\mathrm{b}}(284.7 \mathrm{eV})$ is found compared that of $\mathrm{S}_{\mathrm{a}}(284.2 \mathrm{eV})$ and $\mathrm{S}_{\mathrm{e}}(284.3 \mathrm{eV})$. Increased olefinic $\mathrm{sp}^{2}$ C-bond groups, with shorter bond lengths due to charge neutralization, lead to a stronger interaction between $\mathrm{C}$ atoms and higher binding energy. This results in a highly reduced $\mathrm{sp}^{2}$ structure of $\mathrm{S}_{\mathrm{b}}$ [37]. The corresponding analytical outcomes are summarized in Table S3, Supporting Information File 1. Thus, $S_{b}$ exhibits the highest $\mathrm{sp}^{2}$ carbon structure ratio, compared to $\mathrm{S}_{\mathrm{a}}$ and $\mathrm{S}_{\mathrm{e}}$. According to Figure $4 \mathrm{C}\left(\mathrm{N}\right.$ 1s spectra fitting), $\mathrm{S}_{\mathrm{b}}$ has the highest intensity of pyridinic- $\mathrm{N}$, suggesting that $\mathrm{N}$ atoms are more likely to form pyridinic-N structure during the co-reduction process. The detailed sample data information is presented in Supporting Information File 1, Table S4. The S $2 p$ spectra of $\mathrm{S}_{\mathrm{e}}$ and $\mathrm{S}_{\mathrm{b}}$ reveal the presence of C-S-C (Figure 4D) [38,39]. Overall, XPS and FT-IR results further confirm higher conjugated $\mathrm{sp}^{2} \mathrm{C}$ structures in sample $\mathrm{S}_{\mathrm{b}}$, leading to an enhanced fluorescence intensity.

\section{Carbon nanodots as fluorescent probes for bacteria bioimaging}

To explore the potential applications of the high QY C-dots, the highest QY C-dots, $\mathrm{S}_{\mathrm{b}}$, were selected and first utilized to assess their fluorescent characteristics. As shown in Figure 5A (on commercially available filter paper), the characters cannot be detected in the visible wavelength range. Conversely, under UV excitation $\left(\lambda_{\mathrm{ex}}=365 \mathrm{~nm}\right)$, the blue fluorescent characters "C-dots" are observed (Figure 5B).

After confirming the bright feature behavior, $\mathrm{S}_{\mathrm{b}}$ was further used to evaluate its bioimaging properties and bacteria viability range. First of all, a cytotoxicity quantification related to the applicable C-dot concentration range was assessed. Xag viability was evaluated following incubation with $\mathrm{S}_{\mathrm{b}}$ in the concentration range from 2.5 to $20 \mu \mathrm{g} \mathrm{mL}^{-1}$ for $72 \mathrm{~h}$. A positive control (untreated cells) was provided, whereas different time points were designated within the $72 \mathrm{~h}$ interval. The data are
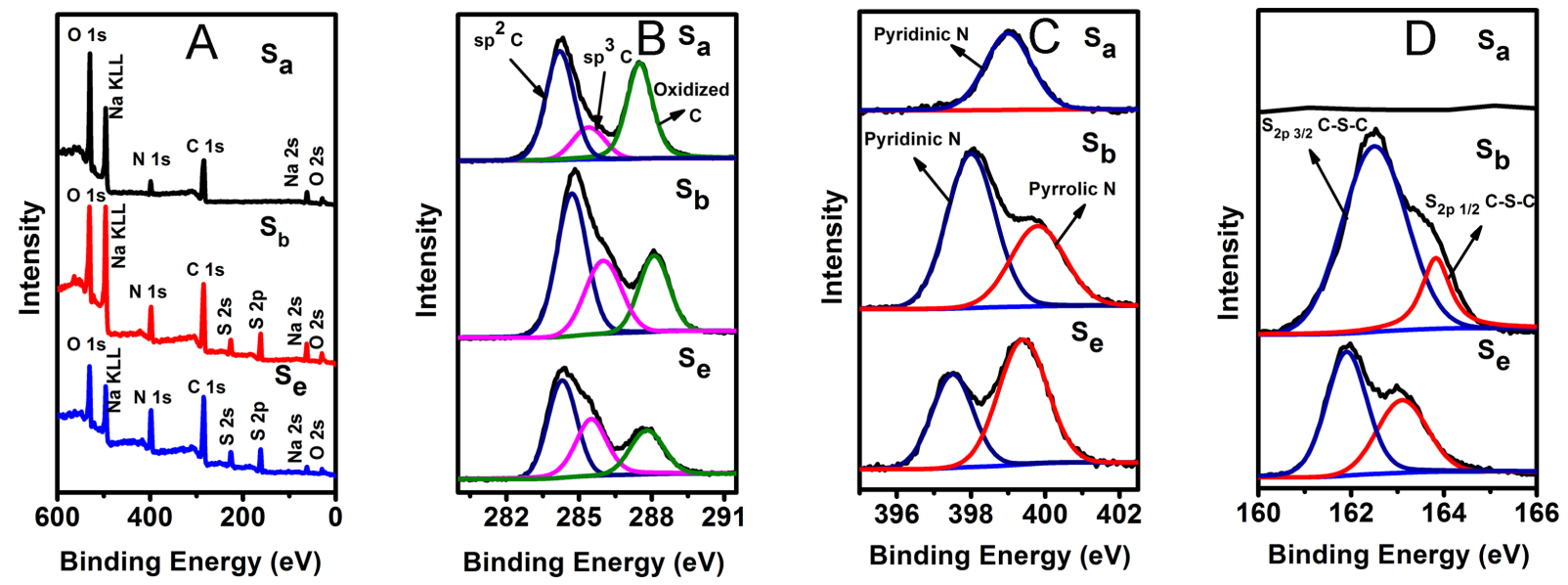

Figure 4: XPS spectra of $S_{a}, S_{b}$, and $S_{e}$. (A) full scan, (B) high-resolution $C$ 1s XPS spectra, (C) high-resolution N 1s XPS spectra, and (D) high-resolution S 2p XPS spectra. 


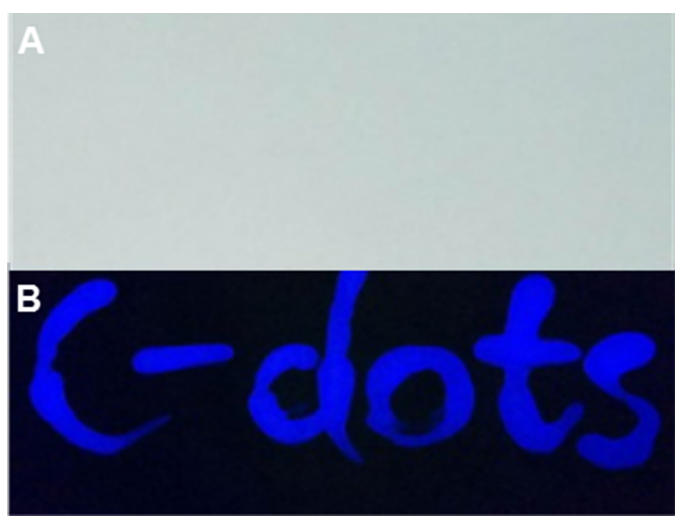

Figure 5: Symbols written on commercially available filter paper using $\mathrm{S}_{\mathrm{b}}\left(5.0 \mu \mathrm{g} \mathrm{m}^{-1}\right)$ captured under $(\mathrm{A})$ daylight and $(B) \mathrm{UV}$ irradiation of $\lambda_{\mathrm{ex}}=365 \mathrm{~nm}$

presented in Figure 6 as the mean \pm standard deviation (SD). The results show that no significant cytotoxicity is reported when the concentration of $\mathrm{C}$-dots is lower than $20 \mu \mathrm{g} \mathrm{mL}^{-1}$ Therefore, C-dots at $20 \mu \mathrm{g} \mathrm{mL}^{-1}$ concentration are considered as the negative control.

Related to the C-dot assay for bioimaging applications, Xag bacteria were incubated and treated for confocal analysis, as detailed in the Experimental section. According to cytotoxicity assay results, $\mathrm{Xag}$ bacteria were incubated with $5.0 \mu \mathrm{g} \mathrm{mL}^{-1}$ of $\mathrm{S}_{\mathrm{b}}$ for $3 \mathrm{~h}$ at $37^{\circ} \mathrm{C}$. As shown in Figure $7 \mathrm{C}$, a strong blue fluorescence is observed with $\lambda_{\mathrm{ex}}=405 \mathrm{~nm}$ excitation, whereas no fluorescence signal is detected from the control sample without $\mathrm{S}_{\mathrm{b}}$ (Figure 7B). Moreover, both treated and untreated cells appear healthy and consistently preserved, as previously observed in cytotoxicity experiments.

\section{Conclusion}

High QY (37\%) C-dots were synthesized using a direct, simple, one-step reduction reaction process with thiourea and urea as

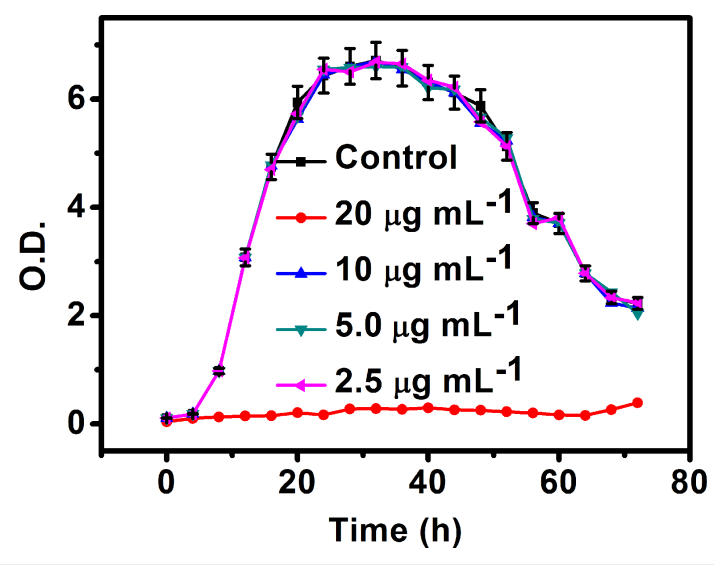

Figure 6: Cytotoxicity towards the bacteria $X a g$ after incubation with $\mathrm{S}_{\mathrm{b}}$ in the concentration range $2.5-20 \mu \mathrm{gL}^{-1}$ for $72 \mathrm{~h}$.

the reducers. Remarkably, the C-dots obtained by the co-reduction showed a highly reduced $\mathrm{sp}^{2}$ structure, bearing a notably high QY. Compared with a conventional two-step chemical reduction pathway, the one-step method is efficient and ecofriendly. Moreover, the obtained C-dots, abundant with the hydrophilic surface, exhibited excellent fluorescent features. On the other hand, a low cytotoxicity for a model bacterial strain Xag was found. Confocal analysis confirmed the suitability of the $\mathrm{C}$-dots as a bioimaging tool for a model bacterial strain, with specific optimal sample synthesis and concentration targeted at this purpose. These unique characteristics look quite promising for the employment of the described systems as fluorescent probes for bioimaging of bacteria Xag.

\section{Experimental \\ Chemicals and materials}

Sodium citrate, urea, and thiourea were purchased from Chemical Reagent Co. Ltd. (Tianjin, China). Xylose and glucose were purchased from Aladdin Ltd. (Shanghai, China). Nutrient broth (NB) medium ( $1 \mathrm{~g} \mathrm{~L}^{-1}$ yeast extract, $3 \mathrm{~g} \mathrm{~L}^{-1}$ beef extract,
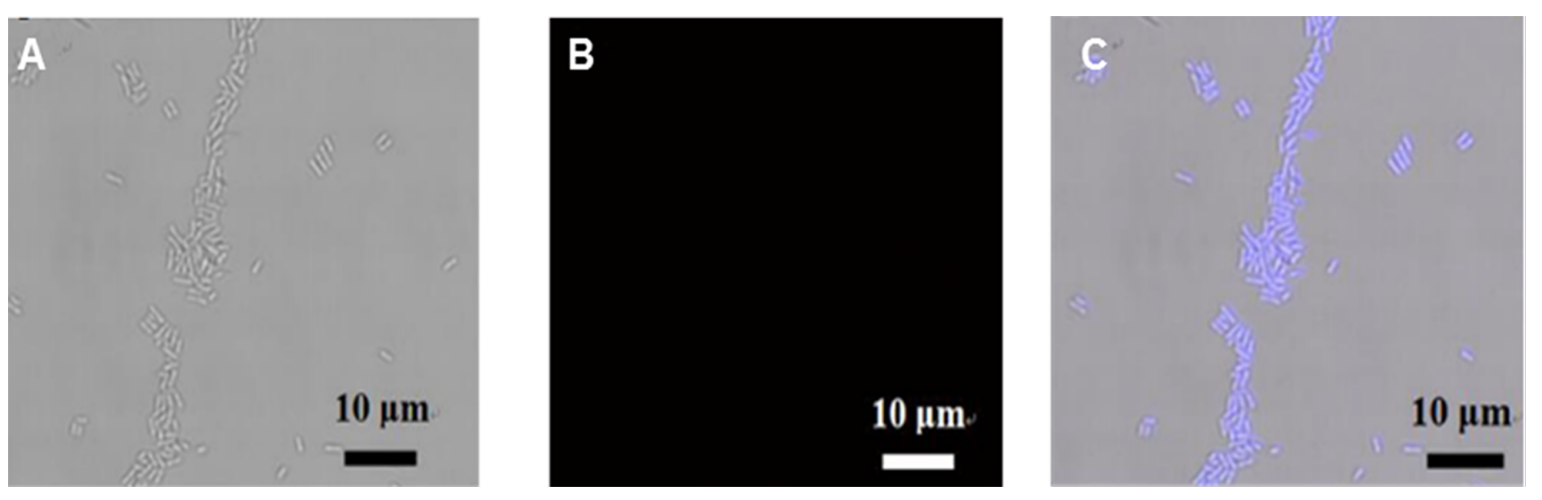

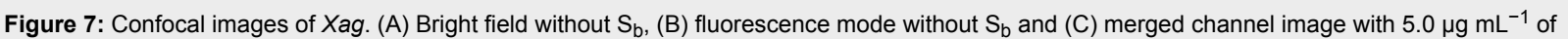
$\mathrm{S}_{\mathrm{b}}$ incubated for $3 \mathrm{~h}$ at $37^{\circ} \mathrm{C}$. 
$5 \mathrm{~g} \mathrm{~L}^{-1}$ poly peptone, $10 \mathrm{~g} \mathrm{~L}^{-1}$ sucrose) was purchased from Sigma-Aldrich. All other chemicals were of analytical grade and used as received. Double distilled water was used in all experiments.

\section{Synthesis of carbon nanodots}

The C-dots were synthesized by mixing different amounts of thiourea, urea or sodium citrate in $30 \mathrm{~mL}$ of distilled water (see Table 1 in Results and Discussion). The aqueous solutions were subsequently transferred to a $50 \mathrm{~mL}$ teflon-lined autoclave and heated at a constant temperature of $185^{\circ} \mathrm{C}$ for $6 \mathrm{~h}$. After the end of the reaction, suspensions with different turbidity were obtained, evidencing the formation of the $\mathrm{C}$-dots. Then, they were dialyzed against deionized water through a dialyzer with a cut off of $M_{\mathrm{W}}=1000 \mathrm{Da}$ for $40 \mathrm{~h}$. Finally, the resulting solutions were vacuum-evaporated in a rotary evaporator at $50{ }^{\circ} \mathrm{C}$ and then freeze-dried to obtain the the $\mathrm{C}$-dot powder. The C-dots were dispersed in ultrapure water as stock solutions $\left(0.5 \mathrm{mg} \mathrm{mL} \mathrm{m}^{-1}\right)$ for further characterization and use. Table 1 (Results and Discussion) shows the samples with different additives obtained and labeled as $\mathrm{S}_{\mathrm{a}}, \mathrm{S}_{\mathrm{b}}, \mathrm{S}_{\mathrm{c}}, \mathrm{S}_{\mathrm{d}}$, and $\mathrm{S}_{\mathrm{e}}$, respectively.

\section{Carbon nanodot characterization}

The product morphology was assessed by TEM and HRTEM, which was performed on JEOL-2100F instrument with an accelerating voltage of $200 \mathrm{kV}$. The XRD patterns of $\mathrm{S}_{\mathrm{a}}, \mathrm{S}_{\mathrm{b}}$, and $\mathrm{S}_{\mathrm{e}}$ were recorded on a Bruker D8 Advance device with a graphite monochromatized $\mathrm{Cu} \mathrm{K} \alpha$ radiation source $(\lambda=1.54056 \AA)$. XRD diagrams were recorded from $10^{\circ}$ to $60^{\circ}$ with a step size of $0.02^{\circ}$ at $3^{\circ} \mathrm{min}^{-1}$. Raman measurements were performed with a Renishaw RM1000 confocal microscope and a He-Ne laser $(633 \mathrm{~nm}, 10 \mathrm{~mW})$. The laser beam was focused to a spot approximately $2 \mu \mathrm{m}$ in diameter with a $50 \times$ microscope objective; the accumulation time was $10 \mathrm{~s}$. Raman spectra were collected from several randomly selected positions on the substrate. Further evidence of the product composition was inferred by means of X-ray photoelectron spectroscopy (XPS), using a K-Alpha XPS spectrometer (Scientific Escalab 250) with an Al Ka X-ray radiation (1486.6 eV) source for excitation. UV-vis absorption spectra of the samples were recorded on a Perkin Elmer Lambda 950 spectrophotometer. FT-IR was conducted at room temperature on a Nicolet 670 spectrometer in the range of $4000-400 \mathrm{~cm}^{-1}$. An LS-45 fluorescence spectrophotometer (Perkin-Elmer, UK) was employed for fluorescence spectroscopy measurements. Confocal images were acquired using a confocal laser scanning microscope (Leica TCS SP5 AOBS).

\section{Fluorescence related experiments}

The relative quantum yield was measured according to the equation [40]:

$$
\phi_{\mathrm{x}}=\phi_{\text {std }}\left(A_{\text {std }} / A_{\mathrm{x}}\right)\left(I_{\mathrm{x}} / I_{\text {std }}\right)\left(\eta_{\mathrm{x}}^{2} / \eta_{\text {std }}^{2}\right),
$$

where $\Phi$ is the quantum yield, $A$ is the optical density, $I$ is the measured integrated emission intensity, and $\eta$ is the refractive index. The subscript "std" indicates the value of a standard reference and "x" for the sample. Quinine sulfate $\left(\Phi_{\text {std }}=0.54\right)$ was used as the standard and was dissolved in $0.1 \mathrm{M} \mathrm{H}_{2} \mathrm{SO}_{4}$ $\left(\eta_{\text {std }}=1.33\right)$ and the C-dots were dissolved in water $\left(\eta_{\mathrm{x}}=1.33\right)$. In order to minimize re-absorption effects, absorbance readings in a $10 \mathrm{~mm}$ fluorescence cuvette were kept near 0.05 at the excitation wavelength $\left(\lambda_{\mathrm{ex}}=360 \mathrm{~nm}\right)$.

Fluorescence lifetime parameters were monitored at room temperature in aqueous solution by using the time-correlated singlephoton counting system in the FLS980 device. An Edinburgh EPL 340 ps pulsed diode laser ( $341.6 \mathrm{~nm}, 701.2 \mathrm{ps}$ pulse width) operated at $200 \mathrm{kHz}$ was used as the excitation source. The fluorescence lifetime $(\tau)$ was fitted by using the Edinburgh FLS980 software package. The average lifetime $(\bar{\tau})$ was calculated according to the following equation

$$
\bar{\tau}=\frac{\sum B_{\mathrm{i}} \tau_{\mathrm{i}}^{2}}{\sum B_{\mathrm{i}} \tau_{\mathrm{i}}},
$$

where $B_{\mathrm{i}}$ is the fractional contribution of the time-resolved decay lifetime of $\tau_{\mathrm{i}}$.

To further prove and demonstrate the fluorescent features of the $\mathrm{C}$-dots, the colorless aqueous solution of the C-dots $\left(\mathrm{S}_{\mathrm{b}}\right.$, $5.0 \mu \mathrm{g} \mathrm{mL}^{-1}$ ) was applied to commercial filter paper using a Chinese brush. The abbreviation " $\mathrm{C}$-dots" was observed under UV lamp excitation $\left(\lambda_{\mathrm{ex}}=365 \mathrm{~nm}\right)$.

\section{Confocal microscopic imaging of bacteria using carbon nanodots as bioimaging probes}

Xanthomonas axonopodis pv. glycins (Xag) strains were used as the bacterial model. Xag were grown in NB medium at $28^{\circ} \mathrm{C}$ for $24 \mathrm{~h} .200 \mu \mathrm{L}$ of $\mathrm{Xag}$ grown in NB medium was then inoculated into $20 \mathrm{~mL}$ of fresh medium and grown in a shaking incubator $(200 \mathrm{rpm})$ at $28^{\circ} \mathrm{C}$ for $18 \mathrm{~h}$. Then, $5 \mathrm{~mL}$ of the bacteria in the middle of an exponential growth phase were collected by centrifugation at $3000 \mathrm{rpm}$ for $10 \mathrm{~min}\left(20{ }^{\circ} \mathrm{C}\right)$ and fixed in $1 \mathrm{~mL} 70 \%$ ethanol for $5 \mathrm{~min}$ at $4{ }^{\circ} \mathrm{C}$. The fixed bacteria were suspended in NB medium containing C-dots $\left(5.0 \mu \mathrm{g} \mathrm{mL}^{-1}\right)$ while shaking for $3 \mathrm{~h}$ at $28{ }^{\circ} \mathrm{C}$. The final bacteria pellets were washed with PBS, resuspended in $200 \mu \mathrm{L}$ of PBS, and then further transferred to a glass slide for confocal imaging using an excitation wavelength of $405 \mathrm{~nm}$. All images were acquired at $630 \times$ magnification. 


\section{Cytotoxicity assay of carbon nanodots for Xag}

The cytotoxicity of C-dots toward Xag was measured in NB medium at $28{ }^{\circ} \mathrm{C}$. Different concentrations of C-dots $(0,2.5$, 5.0, 10 and $20 \mu \mathrm{g} \mathrm{mL}^{-1}$ ) were added into Erlenmeyer flasks and shaken for $2 \mathrm{~min}$ at $180 \mathrm{rpm}$. Furthermore, $0.2 \mathrm{~mL}$ of culture broth was collected at different time points $(0-72 \mathrm{~h})$ and their optical density was measured at $600 \mathrm{~nm}$ in order to calculate the cell viability. Quantification is reported as relative values to the negative control, where the negative control (untreated) is set to $100 \%$ viability.

\section{Supporting Information}

\section{Supporting Information File 1 \\ Additional experimental data.}

The general co-reduction method with urea and thiourea to obtain C-dots, the scale-up synthesis of C-dots, TEM and size distribution of $S_{b 50}$, XRD patterns of $S_{a}, S_{b}$ and $S_{e}$, Raman spectra of $\mathrm{S}_{\mathrm{a}}, \mathrm{S}_{\mathrm{b}}$ and $\mathrm{S}_{\mathrm{e}}$, deconvoluted $\mathrm{C}$ 1s XPS spectra of different $\mathrm{C}$-dots with peak area $(A)$ ratios of the $\mathrm{sp}^{3} \mathrm{C}$ or oxidized $\mathrm{C}$ to the $\mathrm{sp}^{2} \mathrm{C}$ and deconvoluted $\mathrm{N} 1 \mathrm{~s}$ XPS spectra of different C-dots with $A$ ratios of the pyrrolic $\mathrm{N}$ to pyridinic $\mathrm{N}$.

[http://www.beilstein-journals.org/bjnano/content/ supplementary/2190-4286-9-16-S1.pdf]

\section{Acknowledgements}

We are thankful for the support by the Natural Science Foundation of Zhejiang Province (No. LY15C040002) and Science Foundation Ireland (No. 13/CDA/2122).

\section{References}

1. Miao, P.; Han, K.; Tang, Y.; Wang, B.; Lin, T.; Cheng, W. Nanoscale 2015, 7, 1586-1595. doi:10.1039/c4nr05712k

2. Zuo, P.; Lu, X.; Sun, Z.; Guo, Y.; He, H. Microchim. Acta 2016, 183, 519-542. doi:10.1007/s00604-015-1705-3

3. Yuan, F.; Li, S.; Fan, Z.; Meng, X.; Fan, L.; Yang, S. Nano Today 2016, 11, 565-586. doi:10.1016/j.nantod.2016.08.006

4. Padmavathy, T.; Astha, M.; Logan, M. B.; Swadeshmukul, S. Adv. Drug Delivery Rev. 2010, 62, 424-437. doi:10.1016/j.addr.2009.11.014

5. Wiliam, W. Y.; Emmanuel, C.; Rebekah, D.; Vicki, L. C. Biochem. Biophys. Res. Commun. 2006, 348, 781-786. doi:10.1016/j.bbrc.2006.07.160

6. Zhu, S.; Song, Y.; Zhao, X.; Shao, J.; Zhang, J.; Yang, B. Nano Res. 2015, 8, 355-381. doi:10.1007/s12274-014-0644-3

7. Strauss, V.; Margraf, J. T.; Dirian, K.; Syriannis, Z.; Prato, M.; Wessendort, C.; Hirsch, A.; Clark, T.; Guldi, D. M. Angew. Chem., Int. Ed. 2015, 54, 8297-8302. doi:10.1002/anie.201502482
8. Strauss, V.; Margraf, J. T.; Dolle, C.; Butz, B.; Nacken, T. J.; Walter, J.; Bauer, W.; Peukert, W.; Spiecker, E.; Clark, T.; Guldi, D. M. J. Am. Chem. Soc. 2014, 136, 17308-17316. doi:10.1021/ja510183c

9. Sun, Y.-P.; Zhou, B.; Lin, Y.; Wang, W.; Fernando, K. A. S.; Pathak, P.; Meziani, M. J.; Harruff, B. A.; Wang, X.; Wang, H.; Luo, P. G.; Yang, H.; Kose, M. E.; Chen, B.; Veca, L. M.; Xie, S.-Y. J. Am. Chem. Soc. 2006, 128, 7756-7757. doi:10.1021/ja062677d

10. Shen, J.; Zhu, Y.; Chen, C.; Yang, X.; Li, C. Chem. Commun. 2011, 47, 2580-2582. doi:10.1039/c0cc04812g

11. Liu, D.-D.; Su, H.; Cao, Q.; Le, X.-Y.; Mao, Z.-W. RSC Adv. 2015, 5, 40588-40594. doi:10.1039/c5ra04544d

12. Arcudi, F.; Đorđević, L.; Prato, M. Angew. Chem., Int. Ed. 2016, 55, 2107-2112. doi:10.1002/anie.201510158

13. Xu, Q.; Pu, P.; Zhao, J.; Dong, C.; Gao, C.; Chen, Y.; Chen, J.; Liu, Y.; Zhou, H. J. Mater. Chem. A 2015, 3, 542-546. doi:10.1039/c4ta05483k

14. Zheng, H.; Wang, Q.; Long, Y.; Zhang, H.; Huang, X.; Zhu, R. Chem. Commun. 2011, 47, 10650-10652. doi:10.1039/C1CC14741B

15. Tian, R.; Hu, S.; Wu, L.; Chang, Q.; Yang, J.; Liu, J. Appl. Surf. Sci. 2014, 301, 156-160. doi:10.1016/j.apsusc.2014.02.028

16. Shen, R.; Song, K.; Liu, H.; Li, Y.; Liu, H. ChemPhysChem 2012, 13, 3549-3555. doi:10.1002/cphc.201200018

17. Feng, Y.; Zhao, J.; Yan, X.; Tang, F.; Xue, Q. Carbon 2014, 66, 334-339. doi:10.1016/j.carbon.2013.09.008

18. Bourlinos, A. B.; Stassinopoulos, A.; Anglos, D.; Zboril, R.; Georgakilas, V.; Giannelis, E. P. Chem. Mater. 2008, 20, 4539-4541. doi:10.1021/cm800506r

19. Qu, D.; Zheng, M.; Du, P.; Zhou, Y.; Zhang, L.; Li, D.; Tan, H.; Zhao, Z.; Xie, Z.; Sun, Z. Nanoscale 2013, 5, 12272-12277. doi:10.1039/c3nr04402e

20. Li, X.; Zhang, S.; Kulinich, S. A.; Liu, Y.; Zeng, H. Sci. Rep. 2014, 4, 4976-4984. doi:10.1038/srep04976

21. Sun, Z.; Kim, J. H.; Zhao, Y.; Bijarbooneh, F.; Malgras, V.; Lee, Y.; Kang, Y.-M.; Dou, S. X. J. Am. Chem. Soc. 2011, 133, 19314-19317. doi:10.1021/ja208468d

22. Chen, W.; Yan, L.; Bangal, P. R. J. Phys. Chem. C 2010, 114, 19885-19890. doi:10.1021/jp107131v

23. Xiong, S.; Zeng, H. C. Angew. Chem., Int. Ed. 2012, 51, 949-952. doi:10.1002/anie.201106826

24. Liang, J.; Jiao, Y.; Jaroniec, M.; Qiao, S. Z. Angew. Chem., Int. Ed. 2012, 51, 11496-11500. doi:10.1002/anie.201206720

25. Sun, L.; Wang, L.; Tian, C.; Tan, T.; Xie, Y.; Shi, K.; Li, M. RSC Adv. 2012, 2, 4498-4506. doi:10.1039/C2RA01367C

26. Zhu, H.; Wang, X.; Li, Y.; Wang, Z.; Yang, F.; Yang, X. Chem. Commun. 2009, 5118-5120. doi:10.1039/b907612c

27. Lai, T.; Zheng, E.; Chen, L.; Wang, X.; Kong, L.; You, C.; Ruan, Y.; Weng, X. Nanoscale 2013, 5, 8015-8021. doi:10.1039/c3nr02014b

28. Wang, Q.; Zhang, S.; Zhong, Y.; Yang, X.-F.; Li, Z.; Li, H. Anal. Chem. 2017, 89, 1734-1741. doi:10.1021/acs.analchem.6b03983

29. Cheng, C.; Shi, Y.; Li, M.; Xing, M.; Wu, Q. Mater. Sci. Eng., C 2017, 79, 473-480. doi:10.1016/j.msec.2017.05.094

30. Xiong, Y.; Schneider, J.; Reckmeier, C. J.; Huang, H.; Kasák, P.; Rogach, A. L. Nanoscale 2017, 9, 11730-11738. doi:10.1039/c7nr03648e

31. Zhu, S.; Zhao, X.; Song, Y.; Lu, S.; Yang, B. Nano Today 2016, 11, 128-132. doi:10.1016/j.nantod.2015.09.002

32. Shi, L.; Yang, J. H.; Zeng, H. B.; Chen, Y. M.; Yang, S. C.; Wu, C.; Zeng, H.; Yoshihito, O.; Zhang, Q. Nanoscale 2016, 8, 14374-14378. doi:10.1039/c6nr00451b

33. Kasprzyk, W.; Bednarz, S.; Żmudzki, P.; Galica, M.; Bogdal, D. RSC Adv. 2015, 5, 34795-34799. doi:10.1039/c5ra03226a 
34. Mohagheghpour, E.; Moztarzadeh, F.; Rabiee, M.; Tahriri, M.;

Ashuri, M.; Sameie, H.; Salimi, R.; Moghadas, S.

IEEE Trans. NanoBioscience 2012, 11, 317-323.

doi:10.1109/TNB.2012.2210442

35. Knight, D. S.; White, W. B. J. Mater. Res. 1989, 4, 385-393.

doi:10.1557/jmr.1989.0385

36. Zhou, X.; Guo, S.; Zhong, P.; Xie, Y.; Li, Z.; Ma, X. RSC Adv. 2016, 6, 54644-54648. doi:10.1039/c6ra06012a

37. Gao, F.; Zeng, D.; Huang, Q.; Tian, S.; Xie, C.

Phys. Chem. Chem. Phys. 2012, 14, 10572-10578.

doi:10.1039/c2cp41045a

38. Choi, C. H.; Chung, M. W.; Park, S. H.; Woo, S. I.

Phys. Chem. Chem. Phys. 2013, 15, 1802-1805.

doi:10.1039/c2cp44147k

39. Wohlgemuth, S.-A.; White, R. J.; Willinger, M.-G.; Titirici, M.-M.; Antonietti, M. Green Chem. 2012, 14, 1515-1523.

doi:10.1039/c2gc35309a

40. Crosby, G. A.; Demas, J. N. J. Phys. Chem. 1971, 75, 991-1024.

doi:10.1021/j100678a001

\section{License and Terms}

This is an Open Access article under the terms of the Creative Commons Attribution License

(http://creativecommons.org/licenses/by/4.0), which permits unrestricted use, distribution, and reproduction in any medium, provided the original work is properly cited.

The license is subject to the Beilstein Journal of

Nanotechnology terms and conditions:

(http://www.beilstein-journals.org/bjnano)

The definitive version of this article is the electronic one which can be found at:

doi:10.3762/bjnano.9.16 